\title{
Bronchoalveolar lavage cell counts as a predictor of short term outcome in pulmonary sarcoidosis
}

\author{
N M FOLEY, A P CORAL, K TUNG, B N HUDSPITH, D G JAMES, N McI JOHNSON \\ From the Middlesex and Royal Northern Hospitals, London
}

\begin{abstract}
Sixty seven patients with biopsy proven pulmonary sarcoidosis were prospectively studied to determine whether single point bronchoalveolar lavage cell counts were a useful indicator of functional outcome and whether repeated lavage helped in management. The mean follow up period was 25 (range 13-37) months. No patient was having corticosteroid treatment at the time of initial bronchoalveolar lavage. "High intensity alveolitis" (lymphocyte count $\geqslant 28 \%$ ) was present at the initial lavage in $\mathbf{4 2}$ patients. These patients showed a significant improvement in their pulmonary function and chest radiographs over the follow up period whereas patients with "low intensity alveolitis" did not. Of the 42 patients with high intensity alveolitis, 31 had chronic sarcoidosis (duration over two years, mean 80 months). These patients showed a significant improvement in FVC but not in TLCO. Corticosteroids resulted in greater functional and radiological improvement in the patients with high intensity alveolitis than in those with low intensity alveolitis. Repeat bronchoalveolar lavage in 34 patients, mean 8.4 months after the original lavage, showed a weak inverse relation between a reduced lymphocyte count and change in forced vital capacity and isotope uptake on a gallium scan. These correlations were too weak to make repeated cell counts useful in management. Our results suggest that high intensity alveolitis may be a favourable prognostic factor for lung function in pulmonary sarcoidosis, even in patients with chronic disease, but that repeat lavage adds little to the management of the individual patient.
\end{abstract}

\section{Introduction}

A major problem in pulmonary sarcoidosis is the prediction of which patients will develop pulmonary fibrosis. The assessment of disease activity is difficult. Many tests of activity have been devised, the most commonly used adjuncts to plain chest radiography and pulmonary function testing being determination of serum angiotensin converting enzyme activity, ${ }^{1-3}$ gallium-67 lung scanning, ${ }^{45}$ and bronchoalveolar lavage fluid differential cell counts with or without identification of lymphocyte subsets. ${ }^{67}$

The value of lavage fluid cell counts in predicting outcome and in evaluating the need for treatment is not clear. An episode of "high intensity alveolitis" (lymphocyte count $\geqslant 28 \%$ ) in untreated patients may

Address for correspondence: Dr Noeleen Foley, Medical Unit, Middlesex Hospital, London WIN 8AA.

Accepted 16 May 1989 be followed by deterioration in lung function in up to $87 \%$ of cases. ${ }^{8} \mathrm{~A}$ fall in the percentage of lymphocytes was correlated with clinical improvement, as gauged by change in the results of pulmonary function tests, chest radiographs, and values of serum immunological markers. ${ }^{9}$ No correlation between the results of these investigations was found in another study. ${ }^{10}$ That a high initial lymphocyte count is a poor prognostic indicator is now less widely accepted, ${ }^{11}{ }^{12}$ and Ward $e t$ $a l^{13}$ proposed that the disparity between studies was due partly to genetic and racial differences, which influence the mode of presentation of sarcoidosis, ${ }^{14}$ and also to differences in study populations.

The value of the bronchoalveolar lavage findings as a means of assessing the need for treatment and response to treatment has also been reviewed both favourably ${ }^{15}$ and unfavourably. ${ }^{16-18}$ Recently lavage fluid neutrophil counts have been reported to be of greater value than the lymphocyte count in predicting deterioration in lung function. ${ }^{19}$

We investigated whether a single point broncho- 
alveolar lavage was of value in predicting which patients with pulmonary sarcoidosis would improve or deteriorate, and whether repeated lavage had a role in the management of patients with sarcoidosis.

\section{Methods}

\section{PATIENTS}

Sixty seven patients ( 33 male) underwent fibreoptic bronchoscopy and bronchoalveolar lavage for the diagnosis or assessment of the activity of their sarcoidosis. All patients had histologically proved sarcoidosis. Thirty three were white, 24 black, and 10 Asian. Their mean age was 42 years and mean duration of disease at the start of the study was 60 months, with a range from newly presented (13 patients) to 20 years. No patient was having corticosteroid treatment either at the time of initial lavage or during the preceding six months.

A chest radiograph was obtained for all patients before the initial lavage. In addition to the standard 0IV staging system, ${ }^{20}$ chest radiographs were given a quantitative score according to the ILO/UC system, which is based on the numbers of rounded and irregular nodules in the three zones of each lung. ${ }^{21}$ All chest radiographs were read on two separate occasions by one radiologist, in random order and "blind" to the clinical state of the patient.

Pulmonary function tests were performed regularly on all patients throughout the study, usually at three monthly intervals. Values for pulmonary function tests are expressed as percentage of predicted value for age, sex, and height, corrected for racial origin. ${ }^{22}$

Radionuclide (gallium-67) lung scanning was performed on all patients at the time of initial lavage, 180 $200 \mathrm{MBq}{ }^{67} \mathrm{Ga}$ citrate being injected intravenously. A gamma camera image taken 48 hours after injection of gallium was stored on computer and a quantitative scoring system was developed ${ }^{23}$; a region of interest (excluding the hila) was drawn and the concentration of isotope in counts per pixel was recorded for anterior and posterior views of each lung. A mean score for the lung fields was calculated and counts were corrected for background activity on the basis of the epigastric area.

\section{BRONCHOALVEOLAR LAVAGE}

After local anaesthesia with lignocaine and sedation with an intravenous benzodiazepine, fibreoptic bronchoscopy was performed. Prewarmed saline $(180 \mathrm{ml})$ buffered to $\mathrm{pH} 7.2$ with $8.4 \%$ sodium bicarbonate was instilled in $3 \times 60 \mathrm{ml}$ aliquots into the right middle lobe or lingula and recovered by gentle suction into siliconised glass containers. Cells were washed three times in RPMI 1640 (Gibco) and cytospin preparations for differential counting were stained with
Giemsa. For this study "high intensity alveolitis" was defined as a lymphocyte count of $28 \%$ or more of total cells, and "low intensity alveolitis" as a lymphocyte count of less than $28 \%$.

\section{FOLLOW UP}

Patients were seen regularly and assessed by chest radiography and pulmonary function tests. Decisions to treat with corticosteroids were made on clinical grounds, without reference to lavage fluid cell counts. All 67 patients had repeat chest radiography and pulmonary function tests at the end of the study period (mean 25, range 13-37 months after initial lavage). All investigations, including lavage and gallium scanning, were repeated in 34 patients during the follow up period (mean 8.6 , range 4-20 months).

Over the two years of follow up 24 of the 67 patients required oral corticosteroid treatment. Treatment was given for pulmonary disease if at least two of the following criteria were met: increase in pulmonary symptoms, deterioration in FVC or TLCo by $10 \%$ or more, or increased density of pulmonary shadowing on chest radiograph corresponding to an increase of more than two points on the ILO scoring system. Only four patients were treated exclusively for pulmonary sarcoidosis. Four were treated for hypercalcaemia, three for ophthalmic sarcoidosis, and one for cerebral sarcoidosis; the remaining 12 patients had one or more of the following: lupus pernio, bone cysts, lymph node enlargement, hepatic granulomas, splenomegaly, pyrexia, and sarcoidosis of the upper respiratory tract.

\section{STATISTICAL METHODS}

Simple regression analysis was used for continuous variables (for example, lymphocyte and neutrophil percentages and forced vital capacity (FVC) or carbon monoxide transfer factor (TLCO)) and for correlation of changes in these variables. Paired Students' $t$ tests were used to assess the significance of the change from the first to the last measurement in the same patient. Non-parametric testing (Wilcoxon signed rank test) was used for differences between groups of data that did not have a normal distribution.

\section{Result}

INITIAL CLINICAL ASSESSMENT

The chest radiograph was abnormal in 53 patients at the start of the study. Of these, 11 were stage I, 23 stage II, 12 stage III, and seven stage IV (a more detailed breakdown of chest radiographs for patients with high intensity alveolitis and low intensity alveolitis is given in table 1). The mean ILO score for the group at this time was 4.9 (SD 1.2, range 0-18). The mean FVC was $87 \%$ predicted (SD $18 \%$, range $51-125 \%$ ). The mean TLCo was $66 \%$ predicted (SD 20\%, range $24-114 \%$ ). 
Table 1 Chest radiograph stage in patients with initial high intensity and low intensity alveolitis

\begin{tabular}{llllll}
\hline $\begin{array}{l}\text { Alveolitis } \\
\text { intensity }\end{array}$ & \multicolumn{2}{l}{ Stage } & & & \\
\cline { 2 - 6 } & 0 & $I$ & $I I$ & $I I I$ & $I V$ \\
\hline $\begin{array}{l}\text { High } \\
(\mathrm{n}=42)\end{array}$ & 6 & 8 & 19 & 6 & 3 \\
$\underset{(\mathrm{n}=25)}{(\mathrm{W}=25}$ & 8 & 3 & 4 & 6 & 4 \\
\hline
\end{tabular}

\section{INITIAL DATA ON LAVAGE FLUID}

The mean lavage lymphocyte count was $33 \%$ (SD $16.4 \%$ ) and the mean neutrophil count $6.9 \%$ (SD $9.8 \%$ ). Control values for the percentages of cells in lavage fluid in our laboratory are: lymphocytes $10 \%$ (SD 4\%), neutrophils $<1 \%$. On the basis of the initial lavage fluid, 42 patients had high intensity alveolitis and 25 patients low intensity alveolitis. Of the 13 newly diagnosed patients, 11 were in the group with high intensity alveolitis. Of the 24 patients who required corticosteroid treatment, 17 had high intensity alveolitis at the initial assessment. Three of 13 newly

$$
\text { HIA }(n=42) \quad \text { LIA }(n=25)
$$
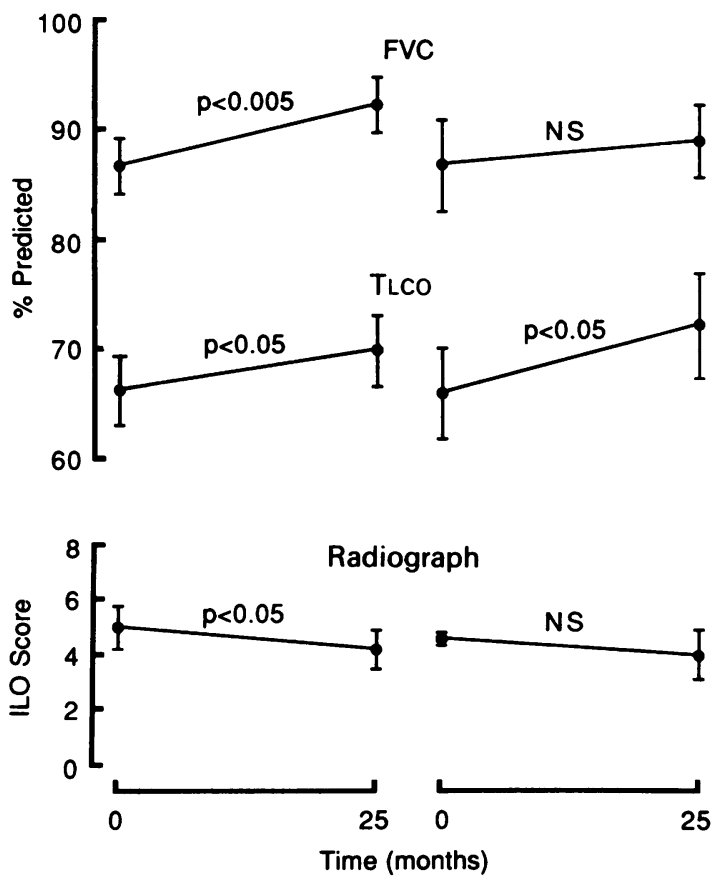

Fig 1 Mean (SD) initial and final measurements of forced vital capacity (FVC), carbon monoxide transfer factor $(T L C O)$, and chest radiograph profusion score in all patients, divided on the basis of initial lavage fluid lymphocyte count: $\geqslant 28 \%$ is designated "high intensity alveolitis" (HIA), $<28 \%$ "low intensity alveolitis" (LIA). diagnosed patients required corticosteroid treatment $\stackrel{\overrightarrow{\vec{S}}}{\overrightarrow{\mathrm{S}}}$ (one each for pulmonary sarcoidosis, ophthalmico sarcoidosis, and hepatosplenomegaly). Of the 34흘 patients who had a repeat lavage during the study, $\frac{\bar{c}}{2}$ only four required treatment between lavages-one $\stackrel{\mathbb{\Phi}}{\propto}$ for pulmonary disease and three for extrapulmonary disease.

\section{PREDICTIVE VALUE OF INITIAL LAVAGE}

There was no significant relation between the initial $\stackrel{\omega}{\mathscr{\omega}}$ lavage lymphocyte count and final outcome, whether $\vec{x}$ judged by FVC, TLCO, or radiological score. Patients with initial high intensity alveolitis, however, showed $a$ significant improvement in pulmonary function and chest radiograph over the two year follow up period $\omega_{N}^{\omega}$ (improvement in FVC: $p<0.001$; TLCO: $p<0.005$;을 ILO score: $p<0.05$ ). Those with low intensity alveolitis showed no significant improvement in FVC 0 or ILO score but their TLCo did improve significantlyo (fig 1). There was no correlation between initial $\frac{\mathbb{\Phi}}{3}$ neutrophil count and change in pulmonary function or chest radiograph, neither was there any significant $\stackrel{\mathbb{}}{-}$ correlation between initial gallium uptake and change $\vec{\emptyset}$ in these measurements.

\section{CHRONIC SARCOIDOSIS}

As patients with "acute sarcoidosis" (particularly with bilateral hilar lymphadenopathy and erythema nodosum) have an excellent prognosis, we analysed $\stackrel{\complement}{\complement}$ the results from the 54 patients who had chronic $\underset{F}{\vec{F}}$ disease separately. Of our 42 patients with high $\frac{9}{3}$ intensity alveolitis, 31 had chronic disease (mean duration 81 (SD 51) months. This group showed significant improvement in FVC over the period of the study ( $p<0.001)$, but there was no significant change 0 in TLCO or ILO score (fig 2). The 14 patients with $\underset{x}{\stackrel{0}{0}}$ chronic disease and high intensity alveolitis who were $\dot{\sigma}$ treated with corticosteroids showed significant improvement in pulmonary function (change in mean $\delta$ FVC from $77 \%$ to $88 \%$ predicted $(p<0.005)$ and in mean TLCo from $55 \%$ to $61 \%$ predicted) and their ILO score fell, though not significantly (fig 3). The untreated patients with chronic disease and high intensity alveolitis showed a small but significant improvement in FVC, and non-significant ${ }^{-5}$ improvements in other pulmonary function $N$ measurements and in their chest radiograph.

Patients with chronic sarcoidosis and low intensity $\sigma$ alveolitis at the onset of the study period (23 patients) showed no improvement in FVC or ILO score but $\stackrel{D}{\mathcal{C}}$ significant improvement in TLCo $(p<0.01$, fig 2$) . \stackrel{?}{+}$ Only seven patients were treated with corticosteroids; 0 they showed no significant change in FVC or TLCo, $\overrightarrow{0}$ but had a fall in ILO score. The 16 untreated patients $\mathbb{尺}$ showed no change in FVC or ILO score, but had a $\mathbb{\mathbb { D }}$ significant rise in TLCO. 

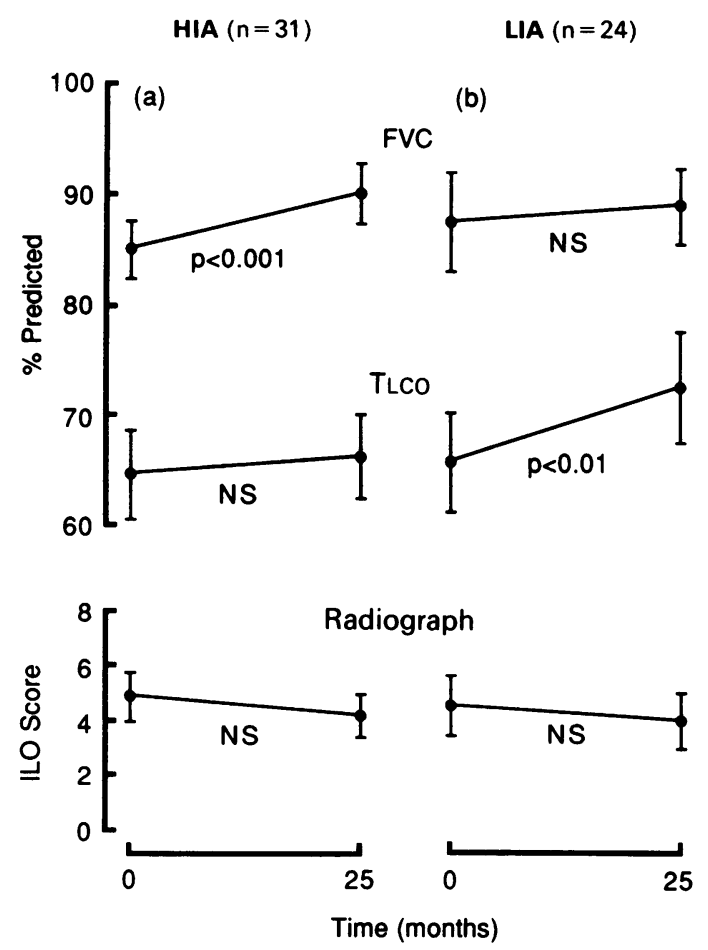

Fig 2 Mean (SD) initial and final forced vital capacity (FVC), carbon monoxide transfer factor (TLCO), and radiographic profusion scores in patients with chronic sarcoidosis (duration over two years, mean 84 months) according to whether the bronchoalveolar fluid showed an initial high intensity (HIA: $\geqslant 28 \%$ lymphocytes) or low intensity alveolitis (LIA).

\section{CORTICOSTEROID TREATMENT AND THE}

NATURAL HISTORY OF THE DISEASE

The 24 patients who required corticosteroid treatment during the course of the study had lower FVC and TLCO values and higher ILO profusion scores at the beginning (table 2), though only four of the patients were treated for pulmonary disease alone. As a group the patients treated showed significant improvement in FVC, TLCO and chest radiograph over the follow up period. The improvement in pulmonary function was quantitatively no greater than that seen spontaneously in the untreated patients, however. Of the four patients treated for pulmonary disease, two showed improvement in both pulmonary function and the chest radiograph, one in function alone, and one in the radiograph alone, All four experienced improvement in symptoms.

The natural history of disease in the 43 untreated patients was for their already near normal FVC to rise

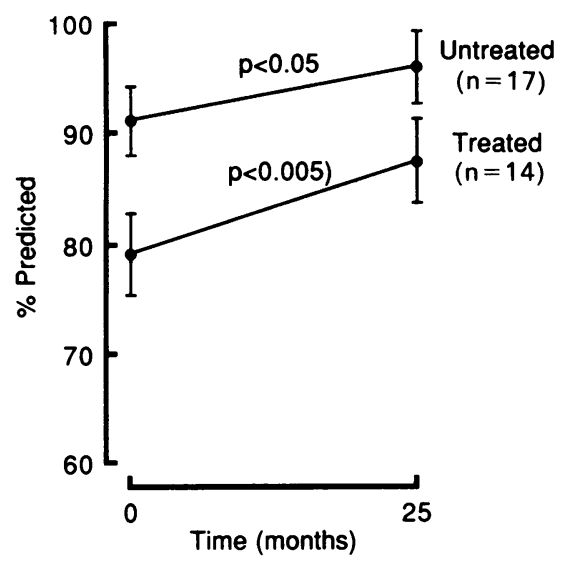

Fig 3 Change in forced vital capacity (FVC) in patients with chronic sarcoidosis and high intensity alveolitis, divided into treated and untreated groups.

(from a mean of $88 \%$ to $92 \%$ predicted), accompanied by a significant rise in TLCo (mean $68 \%$ to $74 \%$; $p<$ 0.05 ), with no significant change in the chest radiograph. Three patients had normal chest radiographs at the beginning of the study, which became abnormal during the course of follow up.

\section{VALUE OF REPEAT LAVAGE}

Lavage was repeated in 34 patients, on average 8.4 months after the initial lavage (range 4-20 months). A significant correlation was found between the fall in lavage fluid lymphocyte percentage and improvement in FVC ( $p<0.05$; fig 4). No correlation was found between change in lymphocyte count and change in TLCO or ILO score. Twenty five patients also had a repeat gallium scan, and a weak correlation was found between fall in the percentage of lymphocytes and fall in gallium score $(p<0.05)$. Change in ILO profusion score was significantly correlated with change in TLCO

Table 2 Mean (SEM) initial and final results of lung function tests (\% predicted) and ILO scores in untreated and treated patients with sarcoidosis

\begin{tabular}{|c|c|c|c|}
\hline . & $F V C$ & TLCO & $I L O$ \\
\hline $\begin{array}{l}\text { Untreated }(n=24) \\
\text { Initial } \\
\text { Final } \\
\text { Significance of difference (p) }\end{array}$ & $\begin{array}{l}88(3) \\
92(3) \\
<0.05\end{array}$ & $\begin{array}{l}68(3) \\
74(3) \\
<0.005\end{array}$ & $\begin{array}{l}3.9(0.6) \\
3.6(0.7) \\
\text { NS }\end{array}$ \\
\hline $\begin{array}{l}\text { Treated }(n=43) \\
\text { Initial } \\
\text { Final } \\
\text { Significance of difference }(p)\end{array}$ & $\begin{array}{l}83(4) \\
89(3) \\
<0.05\end{array}$ & $\begin{array}{l}63(5) \\
66(5) \\
<0.05\end{array}$ & $\begin{array}{l}6.5(1.2) \\
4.9(0.9) \\
<0.05\end{array}$ \\
\hline
\end{tabular}

FVC-forced vital capacity; TLoo-carbon monoxide transfer factor; ILO-International Labour Office chest radiograph score. 
$\Delta \%$

lymphocytes

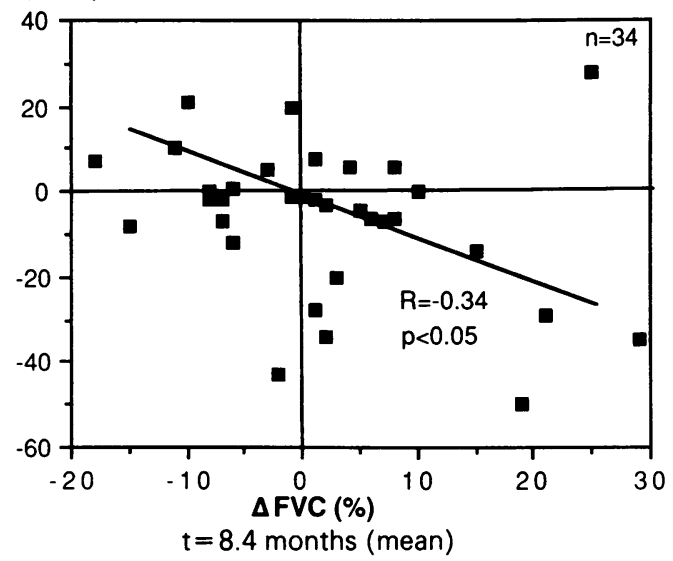

Fig 4 Correlation between changes in \% lymphocytes and forced vital capacity (FVC; \% predicted) over about eight months in 34 patients.

$(p<0.02)$ and change in gallium score $(p<0.04)$.

The percentage of neutrophils tended to rise as the percentage of lymphocytes fell $(p<0.05)$, and a weak correlation was found between a rise in neutrophil count and increase in FVC $(p=0.05)$. This, however, is probably an artefactual association, as the percentage of neutrophils appears to rise as total cell number falls as a result of the fall in lymphocyte number. Overall, the change in neutrophil count was unhelpful with regard to measurement of "disease activity."

\section{ETHNIC DIFFERENCES}

Black patients showed less improvement in pulmonary function than white patients, though there was no significant difference in their chest radiographs. The 10 Asian patients fared worst of all, with considerably worse pulmonary function and chest radiographs than either of the other groups (table 3 ). Forty per cent of

Table 3 Mean (SEM) initial and final results of lung function tests (\% predicted) and ILO profusion scores in different ethnic groups of patients with sarcoidosis

\begin{tabular}{|c|c|c|c|}
\hline & $F V C$ & TLCO & ILO \\
\hline $\begin{array}{l}\text { White }(\mathbf{n}=33) \\
\text { Initial } \\
\text { Final }\end{array}$ & $\begin{array}{l}91(3) \\
96(3)\end{array}$ & $\begin{array}{l}75(4) \\
80(4)\end{array}$ & $\begin{array}{l}4.5(0.7) \\
3.9(0.7)\end{array}$ \\
\hline $\begin{array}{c}\text { Black }(n=24) \\
\text { Initial } \\
\text { Final }\end{array}$ & $\begin{array}{l}86(4) \\
89(3)\end{array}$ & $\begin{array}{l}64(3) \\
65(4)\end{array}$ & $\begin{array}{l}4.9(1 \cdot 1) \\
4.2(0.9)\end{array}$ \\
\hline $\begin{array}{l}\text { Asian }(n=10) \\
\text { Initial } \\
\text { Final }\end{array}$ & $\begin{array}{l}77(4) \\
81(3)\end{array}$ & $\begin{array}{l}55(6) \\
56(6)\end{array}$ & $\begin{array}{l}5.9(2.0) \\
4.7(1.5)\end{array}$ \\
\hline
\end{tabular}

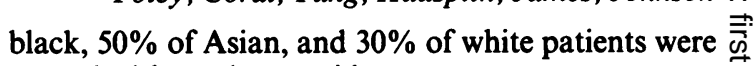
treated with corticosteroids.

\section{Discussion}

Our results suggest that a high lymphocyte percentage in bronchoalveolar lavage fluid is not a poor prognos- $\vec{O}$ tic sign in pulmonary sarcoidosis. Patients with erythema nodosum and bilateral hilar lymphadenopathy $\vec{\omega}$ have a good prognosis, and high intensity alveolitis is $\stackrel{\circ}{\rightleftharpoons}$ of no prognostic significance in this subgroup of $\vec{x}$ patients. Almost all our newly diagnosed patients had very high lymphocyte counts, and most fared well. $\overrightarrow{0}$ This confirms an earlier report that bronchoalveolar lavage at initial assessment is of little value, par- $N$ ticularly in patients with erythema nodosum. ${ }^{24}$ In this $ᄋ$ study patients who had chronic disease with a high $\vec{C}$ lymphocyte count showed a significant improvement $\mathbb{D}$ in FVC over the two year follow up when treated with $\underset{\mathbb{D}}{\stackrel{\mathbb{D}}{\circ}}$ corticosteroids, and the group of patients with chronic disease and a high lymphocyte count who did not $\underset{\mathbb{\Phi}}{\mathbb{D}}$ require treatment on clinical grounds showed no significant deterioration.

Observing the effect of corticosteroid treatment was secondary to the aims of this study, and in most $\square$ patients treatment was for extrapulmonary disease. Corticosteroid treatment was nonetheless associated with modest improvement in pulmonary function and chest radiographs. The patients who responded best to $\stackrel{\square}{\varnothing}$ treatment had high intensity alveolitis as judged by the $\overrightarrow{\vec{P}}$ initial lavage fluid. Those patients who were deemed $\frac{9}{3}$ on clinical grounds not to require treatment improved quantitatively in terms of pulmonary function as much as those who were treated, but they began with near normal pulmonary function and the improvement was $\overline{0}$ not clinically significant. In the patient with chronic $\underset{\times}{\stackrel{\nu}{\otimes}}$ disease for whom treatment is being considered a high $\frac{0}{0}$ lymphocyte count in the lavage fluid may indicate an unstable condition with potential for functional improvement.

We studied a racially mixed group of patients and 0 found that black patients with sarcoidosis tended to have more extrapulmonary manifestations of the disease and required treatment more frequently than white patients, which confirms worldwide experien- or ce. ${ }^{25}$ The few Asian patients in the study had the worst $N$ outcome of all with regard to pulmonary function and $\underset{\mathrm{W}}{\mathrm{N}}$ chest radiographs, showing very little improvement 0 over the two years and requiring corticosteroid treat- 0 ment more frequently than the other ethnic groups, a finding not previously reported. Their number was not $\stackrel{?}{-}$ large enough, however, to draw any firm conclusions 0 from this finding.

The natural history of sarcoidosis is benign and self limiting in most patients. In this study we were $\mathbb{D}$ primarily concerned with outcome in terms of pul- 
monary function. In general, our results bore out the clinical impression, and most patients improved during the follow up period, those with an "acute" presentation doing best. Patients with chronic disease and high lymphocyte counts, however, showed considerably more improvement in lung function than those with low lymphocyte counts, though most of our patients with low intensity alveolitis had better lung function at the outset than those with high intensity alveolitis. Most patients who deteriorated functionally or radiologically belonged to the low intensity alveolitis group at the initial assessment, so that the absence of lymphocytosis did not indicate "burnt out" disease.

Lavage fluid cell counts correlated poorly with clinical measures of disease severity, both at a single point in time and when expressed as change with time. We studied the value of a repeat lavage and, although a significant correlation between several measures was found, notably lavage fluid cell counts and FVC, repeated lavage appears to have little to add to standard pulmonary function tests and chest radiography in management of the individual patient. Abe et $a^{26}$ may be correct in postulating that lavage fluid lymphocytes reflect alveolitis whereas gallium uptake reflects granuloma load, as change in the gallium scan correlated well with change in ILO profusion score and change in TLCo. Lavage fluid cell counts and gallium scanning measure different factors and should therefore be regarded as complementary tests of activity.

We conclude that bronchoalveolar lavage cell counts in pulmonary sarcoidosis add little to the information obtained by standard chest radiography and pulmonary function testing, though in the patient with chronic disease a high lymphocyte count may indicate persistently active alveolitis and thus capacity for improvement.

NMF is funded by the British Lung Foundation.

\section{References}

1 Lieberman J. Elevation of serum angiotensin converting enzyme level in sarcoidosis. Am J Med 1975;59:365-72.

2 Deremee RA, Rohrbach MS. Serum angiotensin converting enzyme activity in evaluating the clinical course of sarcoidosis. Ann Intern Med 1980;92:361-5.

3 Studdy PR, James DG. The specificity and sensitivity of serum angiotensin converting enzyme in sarcoidosis and other diseases: experience in twelve centres in six different countries. In: Chretien J, Marsac J, Saltiel JC eds. Sarcoidosis. Oxford: Pergamon Press, 1983: 332-44.
4 Nasal A, Schleissner LA, Mishkin FS, et al. Angiotensin1 converting enzyme and gallium scan in non-invasive evaluation of sarcoidosis Ann Intern. Med 1979;90: 328-31.

5 Rizzato G. Markers of activity. In: James DG, ed. Sarcoidosis of the respiratory system. Semin Respir Med 1986;8:30-40.

6 Yeager Y, Williams MD, Beekman JF, Bayly TC, Beaman BL, Hawley RJ. Sarcoidosis: analysis of cells obtained by bronchoalveolar lavage. Am Rev Respir Dis 1977;116:951-5.

7 Daniele RP, Elias JA, Epstein PE, Rossman MD. Bronchoalveolar Lavage: Role in the Pathogenesis, Diagnosis and Management of Interstitial Lung Disease. Ann Intern Med 1985;102:93-108.

8 Keogh BA, Hunninghake GW, Line BR, Crystal RG. The Alveolitis of pulmonary sarcoidosis: evaluation of natural history and alveolitis-dependent changes in lung function. Am Rev Respir Dis 1983;128:256-65.

9 Carreiro G, Rottoli P, Rottoli R, Perari MG. Alveolar lymphocytes in the follow-up of sarcoidosis. Allergol Immunopathol 1984;12:337-42.

10 Cohen RD, Bunting PS, Meindok HO, Chamberlain DW, Rebuck AS. Does serum angiotensin converting enzyme reflect intensity of alveolitis in sarcoidosis? Thorax 1985;40:497-500.

11 Israel-Biet D, Venet A, Chretien J. Persistent High Alveolar Lymphocytosis as a Predictive Criterion of Chronic Pulmonary Sarcoidosis. Ann NY Acad Sci 1985;465:395-406.

12 Buchalter S, App W, Jackson L, Chandler D, Jackson R, Fulmer J. Bronchoalveolar lavage cell analysis in sarcoidosis: a comparison of lymphocyte count and clinical course. Ann NY Acad Sci 1985;465:678-84.

13 Ward K, O'Connor C, Odlum C, FitzGerald MX. Prognostic value of bronchoalveolar lavage in sarcoidosis: the critical influence of disease presentation. Thorax 1989;44:6-12.

14 Scadding JG, Mitchell DN. Sarcoidosis. London: Chapman and Hall, 1985:43-71.

15 Costabel U, Bross KJ, Guzman J, Nilles A, Ruhle KH, Matthys $\mathrm{H}$. Predictive value of bronchoalveolar lavage T cell subsets for the clinical course in pulmonary sarcoidosis. Ann NY Acad Sci 1985;465:418-26.

16 Baughman RP, Fernandez M, Bosken CH, Mantil J, Hurtubise P. Comparison of Gallium-67 Scanning, Bronchoalveolar Lavage, and Serum AngiotensinConverting Enzyme Levels in Pulmonary Sarcoidosis: Predicting Response to Therapy. Am Rev Respir Dis 1984;129:676-81.

17 Greening AP, Nunn P, Dobson N, Rudolf M, Rees ADM. Pulmonary sarcoidosis: alterations in bronchoalveolar lymphocytes and $\mathrm{T}$ cell subsets. Thorax 1985;40:278-83.

18 Turner-Warwick M, McAllister W, Lawrence R, Britten A, Haslam PL. Cortocosteroid treatment in pulmonary sarcoidosis: lavage lymphocyte counts, serum angiotensin converting enzyme measurements, and gallium-67 scans help management? Thorax 1986;41:903-13.

19 Lin YH, Haslam PL, Turner-Warwick M. Chronic pulmonary sarcoidosis: relationship between lung 
lavage cell counts, chest radiograph, and results of standard lung function tests. Thorax 1985;40:501-7.

20 Scadding JG. Prognosis of intrathoracic sarcoidosis in England. Br Med J 1961;ii:1165-72.

21 UICC Committee. Cicinnati classification of the radiographic appearances of pneumoconiosis: a cooperative study. Chest 1970;58:57-67.

22 Cotes JE. Lung function: principles and applications in medicine. 3rd ed. Oxford: Blackwell Scientific, 1979:329-87.

23 Duffy GJ, Thirumurthi K, Casey M, et al. Semiquantitative gallium-67 lung scanning as a measure of the intensity of alveolitis in pulmonary sarcoidosis. Eur
J Nucl Med 1986;12:P187-91.

24 Ward K, Odlum C, O'Connor C, Van Breda A, FitzGerald MX. Bronchoalveolar lavage in patients with Erythema Nodosum. In: Grassi C, Rizzato G, Pozzi E, eds. Sarcoidosis and other granulomatous disorders. Amsterdam: Elsevier, 1988:585-6.

25 James DG, Neville E, Siltzbach LE et al. A worldwide review of sarcoidosis. Ann NY Acad Sci 1976;278: $\vec{\circ}$ 321-34.

26 Abe S, Munakata M, Nishimura M, et al. Gallium-67 $\overrightarrow{\vec{\omega}}$ scintigraphy, bronchoalveolar lavage, and pathologic changes in patients with pulmonary sarcoidosis. Chest $\overrightarrow{\vec{x}}$ 1985;85:650-5. 